\title{
The Type III Effector HsvG of the Gall-Forming Pantoea agglomerans Mediates Expression of the Host Gene HSVGT
}

\author{
Gal Nissan, ${ }^{1}$ Shulamit Manulis-Sasson, ${ }^{2}$ Laura Chalupowicz, ${ }^{2}$ Doron Teper, ${ }^{1}$ Adva Yeheskel, ${ }^{3}$ \\ Metsada Pasmanik-Chor, ${ }^{3}$ Guido Sessa, ${ }^{1}$ and Isaac Barash ${ }^{1}$ \\ ${ }^{1}$ Department of Molecular Biology and Ecology of Plants, Faculty of Life Sciences, Tel-Aviv University, Tel-Aviv 69978, \\ Israel; ${ }^{2}$ Department of Plant Pathology and Weed Research, ARO, The Volcani Center, Bet Dagan 50250, Israel; \\ ${ }^{3}$ Bioinformatics Unit, Faculty of Life Sciences, Tel-Aviv University, Tel-Aviv 69978, Israel
}

Submitted 27 June 2011. Accepted 4 October 2011.

\begin{abstract}
The type III effector HsvG of the gall-forming Pantoea agglomerans pv. gypsophilae is a DNA-binding protein that is imported to the host nucleus and involved in host specificity. The DNA-binding region of HsvG was delineated to 266 amino acids located within a secondary structure region near the N-terminus of the protein but did not display any homology to canonical DNA-binding motifs. A binding site selection procedure was used to isolate a target gene of HsvG, named HSVGT, in Gypsophila paniculata. HSVGT is a predicted acidic protein of the DnaJ family with 244 amino acids. It harbors characteristic conserved motifs of a eukaryotic transcription factor, including a bipartite nuclear localization signal, zinc finger, and leucine zipper DNA-binding motifs. Quantitative real-time polymerase chain reaction analysis demonstrated that $H S V G T$ transcription is specifically induced in planta within $2 \mathrm{~h}$ after inoculation with the wild-type $P$. agglomerans pv. gypsophilae compared with the $h s v G$ mutant. Induction of $H S V G T$ reached a peak of sixfold at $4 \mathrm{~h}$ after inoculation and progressively declined thereafter. Gel-shift assay demonstrated that HsvG binds to the HSVGT promoter, indicating that $H S V G T$ is a direct target of HsvG. Our results support the hypothesis that HsvG functions as a transcription factor in gypsophila.
\end{abstract}

Pantoea agglomerans, a widespread epiphyte and commensal bacterium, has evolved to become a host-specific gall-forming pathogen on various hosts (Barash and Manulis-Sasson 2009; Manulis and Barash 2003). P. agglomerans pv. gypsophilae elicits galls on gypsophila (Cooksey 1986) and hypersensitive response (HR) on beet (Ezra et al. 2000), whereas $P$. agglomerans pv. betae causes galls on both beet and gypsophila (Burr et al. 1991). The pathogenicity of P. agglomerans pv. gypsophilae and $P$. agglomerans pv. betae is dependent on the presence of indigenous plasmids designated as $\mathrm{pPATH}_{\mathrm{Pag}}$ and pPATH $_{\text {Pab }}$, respectively (Manulis et al. 1991). The pPATH $\mathrm{Pag}_{\text {of }}$ strain $P$. agglomerans pv. gypsophilae 824-1, which has been more extensively investigated, has a size of $135 \mathrm{~kb}$ harboring a pathogenicity island of approximately $75 \mathrm{~kb}$ that carries a functional hrp/hrc gene cluster (Mor et al. 2001; Nizan et al. 1997), six experimentally confirmed type III effectors (re-

Corresponding author: I. Barash; E-mail: isaaci@post.tau.ac.il

* The $\boldsymbol{e}$-Xtra logo stands for "electronic extra" and indicates that one supplementary figure appears online. ferred to hereafter as effectors) (Barash and Manulis-Sasson 2007), and genes encoding indole-3-acetic acid and cytokinin biosynthetic enzymes (Clark et al. 1993; Lichter et al. 1995). Mutations in any of the $h r p / h r c$ genes encoding the type III secretion system (T3SS) or the hrp regulatory cascade completely abolished gall initiation (Mor et al. 2001; Nizan-Koren et al. 2003), suggesting that gall formation by $P$. agglomerans pv. gypsophilae and P. agglomerans pv. betae is hrp dependent.

HsvG and HsvB are two paralogous effectors present in both $P$. agglomerans pv. gypsophilae and $P$. agglomerans pv. betae that are involved in host specificity on gypsophila and beet, respectively (Nissan et al. 2006). Their structure includes a T3SS recognition motif, a region of predicted $\alpha$ helices, two nuclear localization signals (NLS) present at the $\mathrm{N}$ - and C-terminal regions of the protein, and a transcription activation domain in yeast (Nissan et al. 2006; Weinthal et al. 2011). The two effectors are mainly distinguished by the presence of two direct repeats (71 and 74 amino acids [aa]) in the transcription activation domain of HsvG as opposed to only one of the repeats in the activation domain of HsvB (Nissan et al. 2006). Exchanging the activations domains between $\mathrm{HsvG}$ and HsvB results in a switch in host specificity. A modified yeast two-hybrid assay revealed that either one of the repeats in HsvG or the single repeat of HsvB is sufficient to activate transcription in yeast (Nissan et al. 2006). Transient expression of green fluorescent protein (GFP)HsvG or GFP-HsvB fusions obtained by particle bombardment of gypsophila, beet, or melon (non-host) showed that these effector proteins are localized to the cell nucleus in host and non-host plants (Nissan et al. 2006). Two NLS present in the Nand C-terminal regions of $\mathrm{HsvG}$ and $\mathrm{HsvB}$ are responsible for nuclear import of these effectors (Weinthal et al. 2011). By employing random binding-site selection (Okuno et al. 2001) and electrophoretic mobility shift assays, HsvG and HsvB were demonstrated as DNA-binding proteins with a consensus binding site corresponding to ACACC/aAA (Nissan et al. 2006). The characterization of HsvG and HsvB as DNA-binding proteins, which are imported into plant nucleus via the NLS and act as transcription activators in yeast, could suggest that they might also function as transcription factors in their host plants.

Type III effectors of phytopathogenic bacteria that act as specific transcription factors in their hosts are mainly represented by the large AvrBs3/PthA family of Xanthomonas spp. (Boch and Bonas 2010). Members of this family have been termed transcription-activator-like (TAL) effectors. They are characterized by an N-terminal T3SS recognition domain, a central domain comprising a variable number of tandemly arranged near- 
perfect repeats of 33 to 35 aa, C-terminal NLS, and a eukaryotic acidic transcription-activation domain (Bogdanove et al. 2010; Gurlebeck et al. 2006). Specificity of TAL effectors is determined by a novel modular DNA-binding domain (Boch et al. 2009; Moscou and Bogdanove 2009). A few corresponding target genes for TAL effectors have been identified (Boch and Bonas 2010). Noteworthy are the genes upregulated by AvrBs3 (UPA genes) in pepper (Marois et al. 2002). A conserved promoter element, designated as the UPA box, was found in several induced UPA genes which are directly bound and activated by AvrBs3 (Kay et al. 2009; Römer et al. 2009)

The present study was undertaken to test the notion that HsvG functions as a specific transcription factor in gypsophila. To approach this aim, the DNA-binding region of HsvG was delineated and an HsvG target gene that was transcriptionally induced in an effector-specific manner was isolated and characterized.

\section{RESULTS}

Delimitation of the DNA-binding region of HsvG.

To locate the DNA-binding domain of HsvG, the $h s v G$ open reading frame (ORF) was cloned by polymerase chain reaction
(PCR) into the expression vector pFLAG-ATS and eight deletions were generated (as described below) (Fig. 1A). HsvG deletion mutants were analyzed by gel-shift assay for their ability to bind the DNA consensus sequence ACACAAA, previously determined as the binding site of wild-type HsvG (Nissan et al. 2006) (Fig. 1B). Various deletions between amino acids 107 and 373 abolished binding of HsvG to its target DNA binding site, delineating the maximal site of the DNA-binding motif, whereas deletions of 8 to 107 or 373 to 655 aa did not affect binding, suggesting that neither the repeat domain nor the $\mathrm{N}$ - or C-terminal regions of the protein are involved in binding. Consensus secondary structure predictions of HsvG by the bioinformatics servers Porter, Jpred, and PSIPRED (described below) indicated that the DNA-binding domain is located within a critical secondary structure of the protein, which contains $14 \alpha$ helices and a $\beta$ strand (Fig. 1A). However, attempts to relate the DNA-binding domain to helix-turn-helix (HTH) or any other canonical DNAbinding structures were negative, suggesting that the DNA-binding domain of HsvG represents a new DNA-binding motif. Although several $\alpha$ helices and $\beta$ strands were also detected in the $\mathrm{N}$ - and $\mathrm{C}$-terminal regions of HsvG outside the DNA binding domain, they did not affect DNA binding (Fig. 1A).

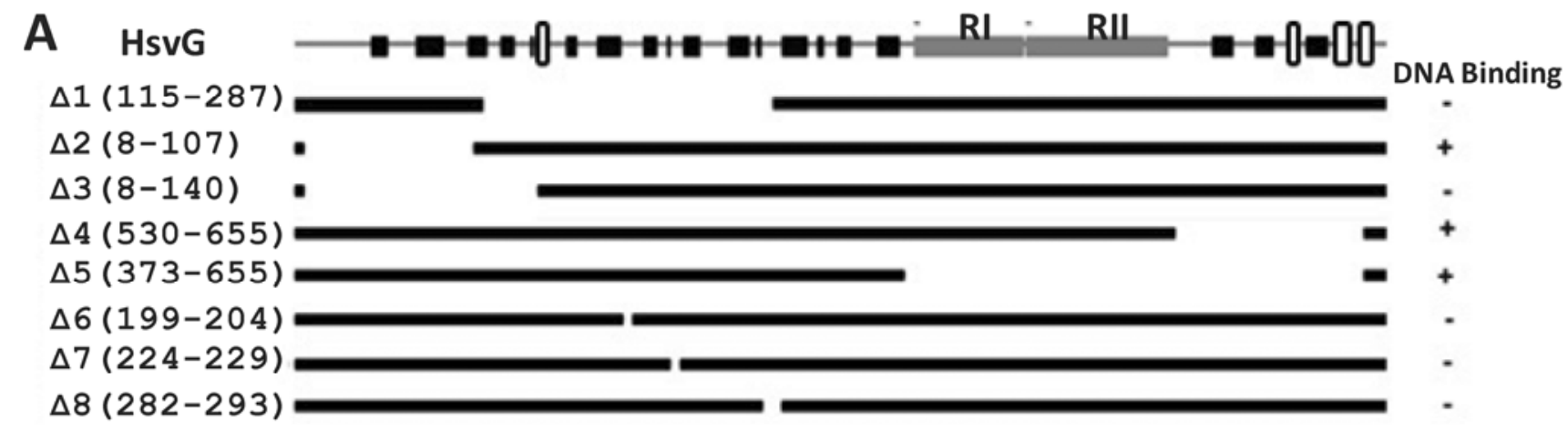

\section{Fold recognition}
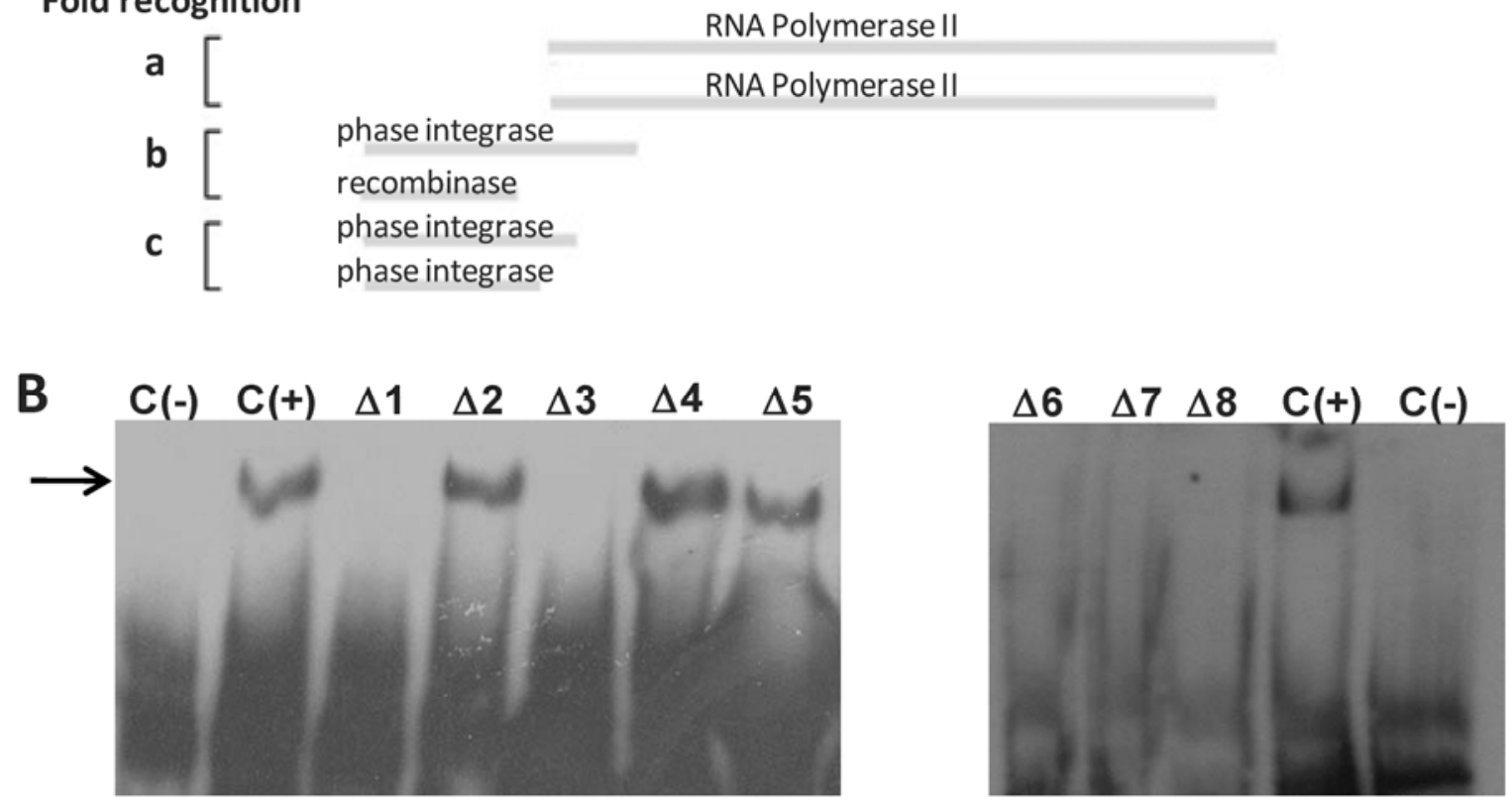

Fig. 1. Delineating the DNA-binding region of HsvG. A, Deletion mutants and secondary structures of HsvG. Top panel illustrates the consensus secondary structure prediction of HsvG. Black rectangles indicate $\alpha$ helices whereas vertical open rectangles indicate $\beta$ strands. The location of the two repeats (RI and RII) is shown by gray rectangles. Middle panel illustrates schematic representation of HsvG deletion mutants ( $\Delta 1$ to $\Delta 8)$. Positive and negative DNA binding is marked by $(+)$ and (-) signs, respectively. Bottom panel shows results of fold recognition obtained by three different methods showing similarity to RNA polymerase II (amino acids 143 to 553; a, FFASO3). Recombinase (amino acids 50 to 140; b, HHPRED and c, 3D-Jury) and phase integrase (amino acids 52 to 160; c, 3D-Jury). B, Gel-shift assay of the corresponding deletion mutants with the ACACAAA consensus binding site. C(+) and C(-) refer to positive (hHsvG with the double-stranded DNA consensus sequence) and negative (DNA without consensus) controls, respectively (Nissan et al. 2006). Arrow points to DNA-bound protein. The DNA-binding region was identified between amino acids 107 and 373 and contained $10 \alpha$ helices and $5 \beta$ strands. 
Fold recognition was predicted by three different bioinformatics methods (as described below) and the two top best results of each prediction are shown in Figure 1A (bottom panel). The fold prediction of HsvG by FFAS03 (Fig. 1A-a) was found to match RNA polymerase II between approximately 143 and 553 aa, recombinase was predicted by HHpred (Fig. 1A-b) and 3D-Jury between approximately 50 and 140 aa, and phase integrase by 3D-Jury (Fig. 1A-c) between 52 and 160 aa. All of the foregoing three proteins are known to interact directly with DNA. The observation that the fold prediction with the matched proteins partially overlapped with the DNAbinding region suggests that it shares similar major secondary structures and topological connections with these proteins.

\section{Identification and characterization}

\section{of a putative target gene for HsvG in gypsophila.}

The identification of an HsvG putative target gene in gypsophila was achieved by employing the binding site-selection (BSS) procedure with hHsvG (HsvG labeled with histidine tag) (as described below) (Fig. 2). Inserts from randomly selected colonies were sequenced and screened for a putative ORF using the software ORF finder (National Center for Biotechnology Information [NCBI]). A 400-bp fragment, which contained the beginning of an ORF and the consensus HsvG binding site (Nissan et al. 2006), was repeatedly isolated. The sequence of $337 \mathrm{bp}$ upstream of the translation start site, predicted to harbor the promoter, is presented in Figure 3A. The full mRNA sequence was obtained by employing the $3^{\prime}$ random amplification of cDNA ends (RACE) procedure. A 1.1-kb fragment containing an ORF of 732 bp and a predicted protein of 244 aa was obtained (Fig. 3B). The isolated target gene of HsvG in gypsophila was designated as HSVGT and submitted to the GenBank as accession number GQ923819.

The promoter region of $H S V G T$ containing the consensus HsvG-binding site ACACAAA (Nissan et al. 2006) was located 263 bp upstream of the ATG start codon (Fig. 3A). Predictions made by the MEME-ChIP server discovered two motifs which are characteristic of eukaryotic promoters: AAACC $[\mathrm{CT}](E$ value $1.1 \mathrm{e}+002)$, and T[GCT][AC][GT][GC]GTT ( $E$ value 1.3e + 001) (Fig. 3A, A and B brackets, respectively). A TATAbox prediction made according to Milanesi and associates (1996) revealed two typical motifs, GTTATAACTC and CCTT TAAATT (Fig. 3A, C and D brackets, respectively).

Sequences homologous to HSVGT protein were found using a CS-Blast search (Biegert and Soding 2009) on NCBI and Uniprot databases. Hypothetical proteins were omitted and the resulting 38 homologs (Supplementary Fig. S1) were aligned using Mafft (Katho et al. 2002). The deduced amino acids of HSVGT showed highest homology to hypothetical DnaJ proteins from various plants but lacked the J-like domain, which is important for the chaperon function (Cheetham and Caplan 1998). Maximal homology was obtained with a DnaJ heatshock N-terminal domain containing protein from Helianthus annuus (GI 211953609) 0.221 (134 aa), heat-shock protein from Brachypodium distachyon (GI 193848480) 0.236 (208 aa), DnaJ domain-containing protein from Oryza sativa Japonica Group (GI 115488688) 0.208 (125 aa), and DNAJ heat-shock $\mathrm{N}$-terminal domain-containing protein from Arabidopsis thaliana (GI 15221189) 0.185 (140 aa). Conservation analysis of the amino acids of HSVGT with proteins of the DnaJ family,

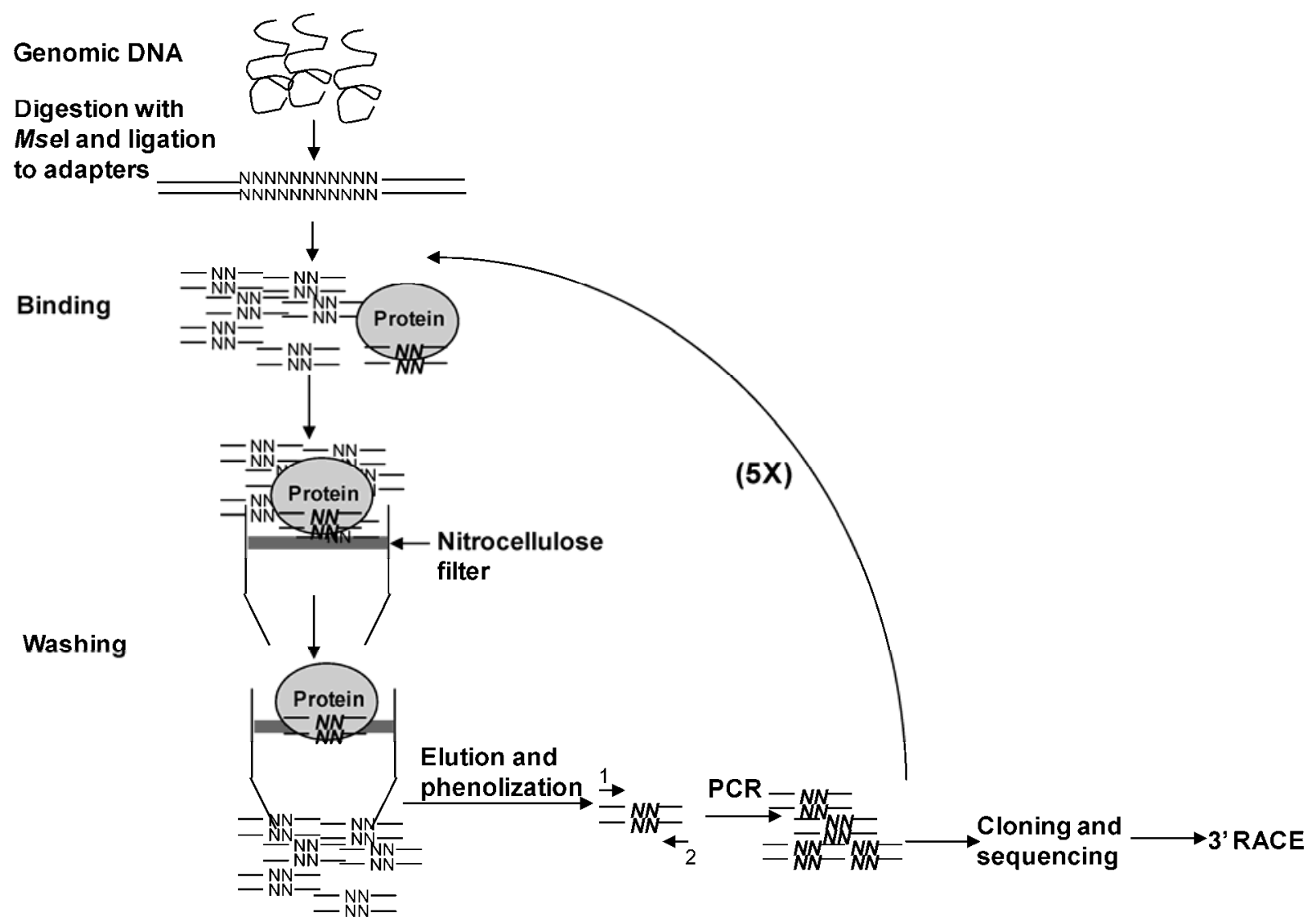

Fig. 2. Schematic presentation of the binding-site selection (BSS) procedure. Genomic DNA of gypsophila was digested with MseI, ligated to adaptors, and transferred to a binding mixture containing purified hHsvG. Following incubation, the solution was passed through a nitrocellulose filter, washed three times with the binding buffer, and eluted with an elution buffer. The eluate was phenolized and polymerase chain reaction amplified with primers that complemented the adaptors. This procedure was repeated five times prior to cloning of the recovered DNA and transformation into Escherichia coli. Thirty colonies were randomly selected for sequencing. The target gene (HSVGT) appeared most frequently (approximately 80\%) in two independent experiments. 
performed by the Conseq server (Berezin et al. 2004), showed that $45.7 \%$ of the amino acids were highly or moderately conserved (Fig. 3B).

A search for domains on the HSVGT protein (Fig. 3B) identified a bipartite NLS predicted by the Predict NLS server, and two DNA-binding domains, namely, a zinc-finger $\mathrm{C}_{2} \mathrm{H}_{2}$ type $\left(\mathrm{ZnF} \_\mathrm{C} 2 \mathrm{H} 2\right)$ and a basic leucine zipper (bZIP), were predicted by the DBS-ÜPRED and the DB-Bind servers, respectively. A site for SUMOylation (Fig. 3B) was predicted by the SUMOsp 2.0 server. The HSVGT is an acidic protein with an isoelectric point of 4.97. Stretches of acidic amino acids (Fig. 3B) (namely, glutamate and aspartate, 51 to 62 and 179 to 193 aa, respectively) could serve as potential activation domains (Latchman 2008). All of the above-mentioned domains are characteristic of transcription factors and could support the hypothesis that HSVGT might be involved in transcriptional activation.

\section{HsvG induces HSVGT expression in planta.}

The expression of HSVGT in gypsophila cuttings inoculated with the wild-type strain $P$. agglomerans pv. gypsophilae 824-1 and its $h s v G$ mutant (P. agglomerans pv. gypsophilae $\mathrm{MxhsvG)}$ was determined at early stages after inoculation by quantitative reverse-transcription (qRT)-PCR (Fig. 4). Results demonstrate an increase of more than three times in the transcripts level of HSVGT within $2 \mathrm{~h}$ postinoculation (hpi), reaching a peak of approximately 6-fold at $4 \mathrm{hpi}$ and a decline to 3.5- and 2-fold after 6 and 8 hpi, respectively. These results suggest that HsvG induces the transcription of its target gene, HSVGT, during a very early stage of disease development.

To investigate whether HsvG might directly activate $H S V G T$ transcription, its binding to the promoter region of HSVGT was examined by a gel-shift assay (Fig. 5). Results obtained illustrate that HsvG binds to double-stranded (ds)DNA generated by annealing the oligonucleotides Bind-Gt-dCo and Bind-GtrCo (Table 1), which harbor the promoter region with the consensus sequence ACACAAA (Fig. 5). In contrast, no binding was obtained with dsDNA generated by the oligonucleotides Bind-Gt-d-non and Bind-Gt-r-non that cover the same promoter region but lack the consensus sequence. The findings that HsvG physically binds to the $H S V G T$ promoter, together with the rapid induction in $H S V G T$ transcription, strongly suggest that HsvG acts as a transcription activator in gypsophila.

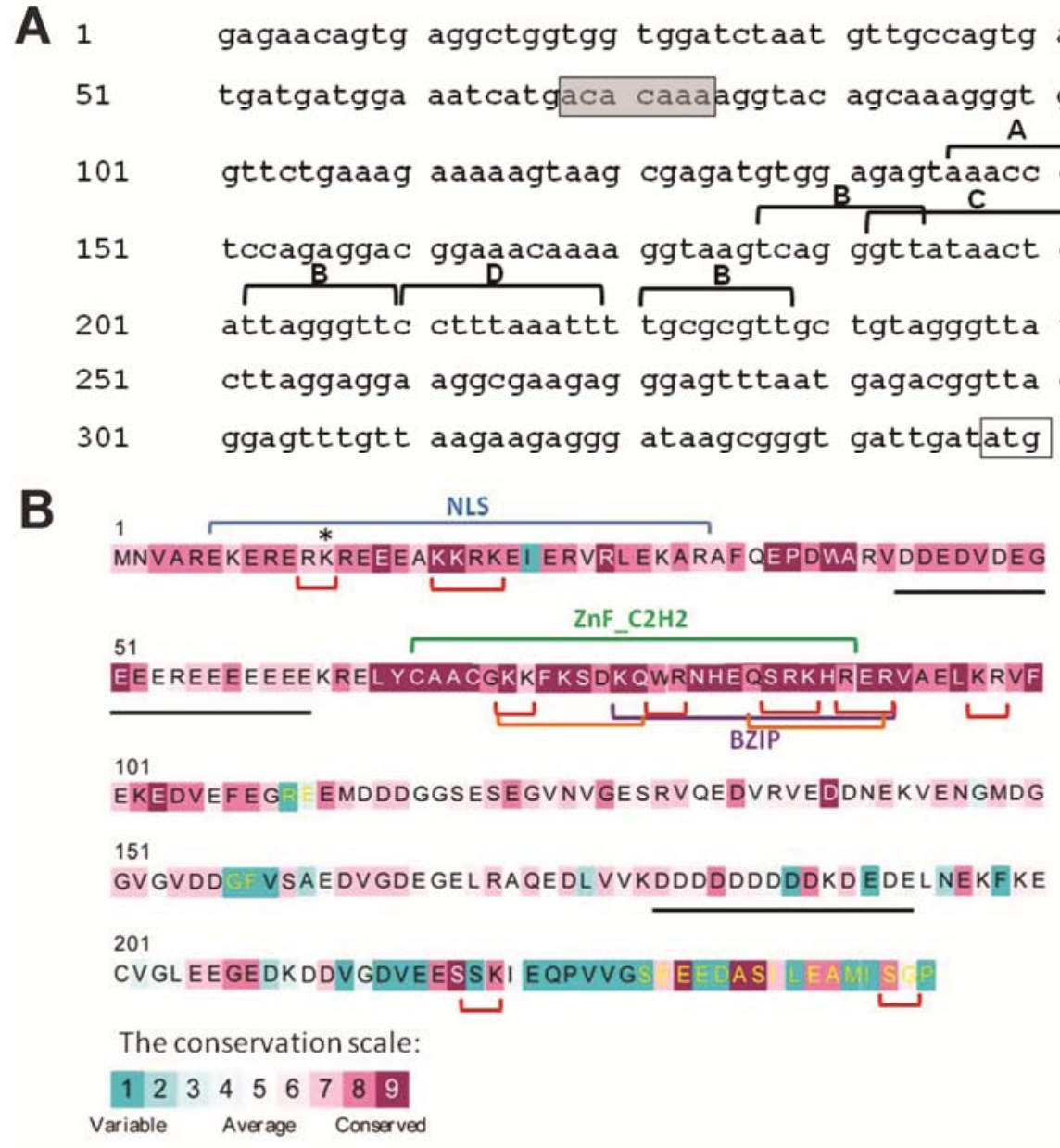

Fig. 3. Sequence of the HsvG target gene. A, Promoter region of HSVGT; 337 bp upstream of the transcription start codon (ATG, marked by clear box) is shown. The promoter contains the consensus HsvG binding site ACACAAA (gray box). Other motif predictions, which are marked by black lines above the sequence, are based on bioinformatics tools MEME ChIP motifs, where bracket A = AAACC [CT] $(E$ value $1.1 \mathrm{e}+002)$ and bracket $\mathrm{B}=\mathrm{T}[\mathrm{GCT}]$ [AC][GT][GC]GTT ( $E$ value 1.3e + 001), and TATA-box prediction motifs, marked by C and D brackets. B, Deduced amino acid sequence of HSVGT. An open reading frame of 244 amino acids (aa) is shown. Conservation score with the DnaJ family was obtained by the neighbor-joining with maximum likelihood method and amino acids are colored by conservation scale (ConSeq) shown below the sequence. Conserved residues are colored magenta and variable residues are cyan. Yellow letters present uncertain conservation prediction. The percentage of amino acids in conservation grade $8 / 9$ is $45.7 \%$. Domain search revealed a bipartite nuclear localization signal (blue line) (6 to 34 aa); zinc-finger $\mathrm{C}_{2} \mathrm{H}_{2}$ type $(\mathrm{ZnF}$ - $22 \mathrm{H} 2)$ is designated by a green line (65 to $95 \mathrm{aa}$ ); and basic leucine zipper (bZIP) (78 to $92 \mathrm{aa}$ ) is indicated by a purple line. The highly predicted SUMOylation site is marked by an asterisk. DNAbinding predictions are shown by red (DBS-PRED) and orange (DB-Bind) lines below the sequences. Black lines below the sequence indicate stretches of the negatively charged amino acid residues, glutamic acid (E) (51 to 62 aa) and aspartic acid (D) (179 to 193 aa). 


\section{HSVGT is upregulated}

by HsvG in an effector-specific manner.

The specificity of HsvG as a transcription factor of $H S V G T$ in gypsophila was tested by complementation of the P. agglomerans pv. gypsophilae mutant in $h s v G$ ( $P$. agglomerans pv. gypsophilae MxhsvG) with $h s v G, h s v B$, and $h s v B$ converted into $h s v G$ (Nissan et al. 2006) (Fig. 6). Results indicate that complementation with $h s v G$ could restore transcription of HSVGT. In contrast, complementation with hsvB (pLHsvB8) could not restore expression of this target gene. However, $h s v B$ converted to $h s v G$ by exchange of the repeat domain $(\mathrm{pLHsvB} \rightarrow \mathrm{G})$ (Table 2) could fully restore induction of HSVGT. Moreover, no significant difference in transcriptional induction could be observed between the $P$. agglomerans pv. gypsophilae-hsvG mutant and mock inoculation (Fig. 4), suggesting that only HsvG and not other effectors that presumably are expressed by the mutant strain can activate $H S V G T$.

\section{DISCUSSION}

Deletion analysis of the HsvG protein followed by a binding assay to the DNA consensus sequence delineated the maximal DNA-binding region to 266 aa near the $\mathrm{N}$ terminus of the protein. This region is associated with a critical secondary structure, including many $\alpha$ helices and a $\beta$ strand (Fig. 1). Moreover, fold-recognition analysis predicted similarity to proteins that interact with DNA such as RNA polymerase II, recombinase, and phase integrase, indicating that HsvG might share the same major secondary structures in the same arrangement and with the same topological connections. Previous analysis predicted the presence of the HTH domain in the N-terminus region of HsvG (Nissan et al. 2006). However, an extensive bioinformatics analysis with three different servers could not predict this motif or any other canonical DNA-binding domain within the borders of the identified DNA-binding domain. The precise structure of the HsvG DNA-binding domain should await the solution of the three-dimensional structure of HsvG. It is noteworthy that deletion of the repeat domain, which is

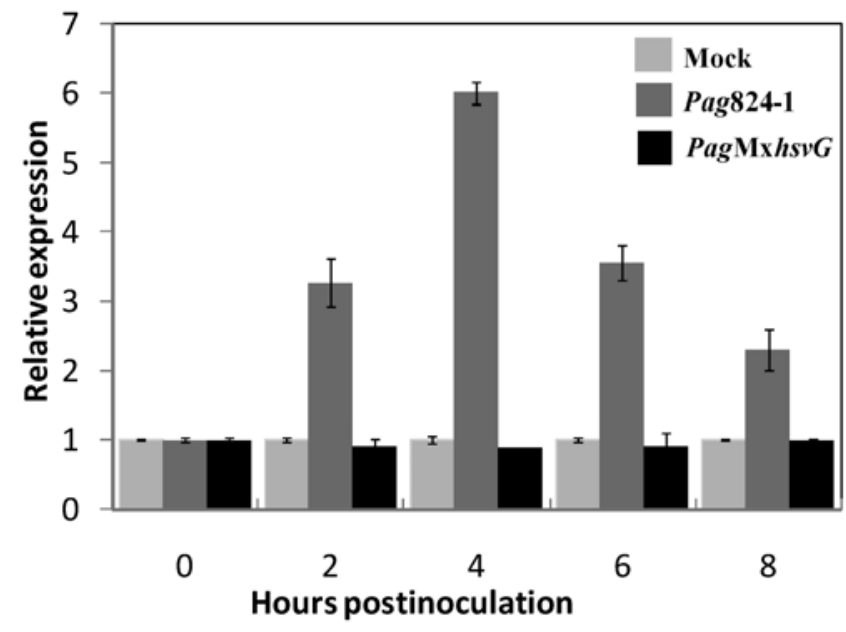

Fig. 4. Transcript levels of HSVGT in inoculated gypsophila cuttings with strain Pantoea agglomerans pv. gypsophilae 824-1 and its marker exchange mutant at various time intervals postinoculation. Cuttings were inoculated by dipping in bacterial suspensions $\left(10^{8} \mathrm{CFU} / \mathrm{ml}\right)$ or mock inoculated with $10 \mathrm{mM} \mathrm{MgCl}{ }_{2}$ solution. Total RNA was extracted from cutting samples collected at various hours postinoculation and used for determination of $H S V G T$ expression by quantitative reverse-transcription polymerase chain reaction analysis. Relative levels of $H S V G T$ were normalized with $\beta$-actin, glyceraldehyde-3-phosphate dehydrogenase, and ATPase as internal references. Values are the average of three independent experiments with standard deviation. Each experiment included three replicates. responsible for both host specificity and transcriptional activation of HsvG in yeast (Nissan et al. 2006), did not show any effect on DNA binding to the consensus sequence (Fig. 1). In contrast to HsvG, the DNA-binding domain of the AvrBs3/PthA family of Xanthomonas spp. is located in the repeat domain, which was also responsible for host specificity (Boch and Bonas 2010), indicating a fundamental difference between these two classes of effectors.

Although both transcription factors obviously have activation activity in yeast and similar DNA-binding capacities, we are still at a loss to explain the plant specificity of each protein. One possibility could be that the specificity arises not from any specific host factors but simply because the double-repeat protein is unstable in beet and the single-repeat protein is unstable in gypsophila. Thus, the proteins would not be active in the foreign environment. Another possibility would be that additional specific host factors are needed to assure transcriptional activation and these factors would be specific to binding either the single-repeat or double-repeat proteins under in vivo conditions. Proteomic studies of the infected hosts in which HsvG and HsvB can be identified by specific antibodies might be useful in supporting or rejecting this speculation.

The HSVGT target gene for HsvG in gypsophila was isolated by a BSS in vitro procedure (Fig. 2) and was shown to be transcriptionally induced promptly following host inoculation in an effector-specific manner (Figs. 4 and 6). Blast analysis indicates that the HSVGT protein belongs to the DnaJ family but lacks the J-domain, which is responsible for chaperon activity (Kelly 1998). The DnaJ family proteins are widely distributed in prokaryotes and eukaryotes and act as co-chaperons of the heatshock protein Hsp70, a major component of the cellular chaperone network and stress response (Hennessy et al. 2005). The $\mathrm{J}$-domain is the major binding site required for the interaction between the DnaJ and Hsp70. It is noteworthy that HopI1, a

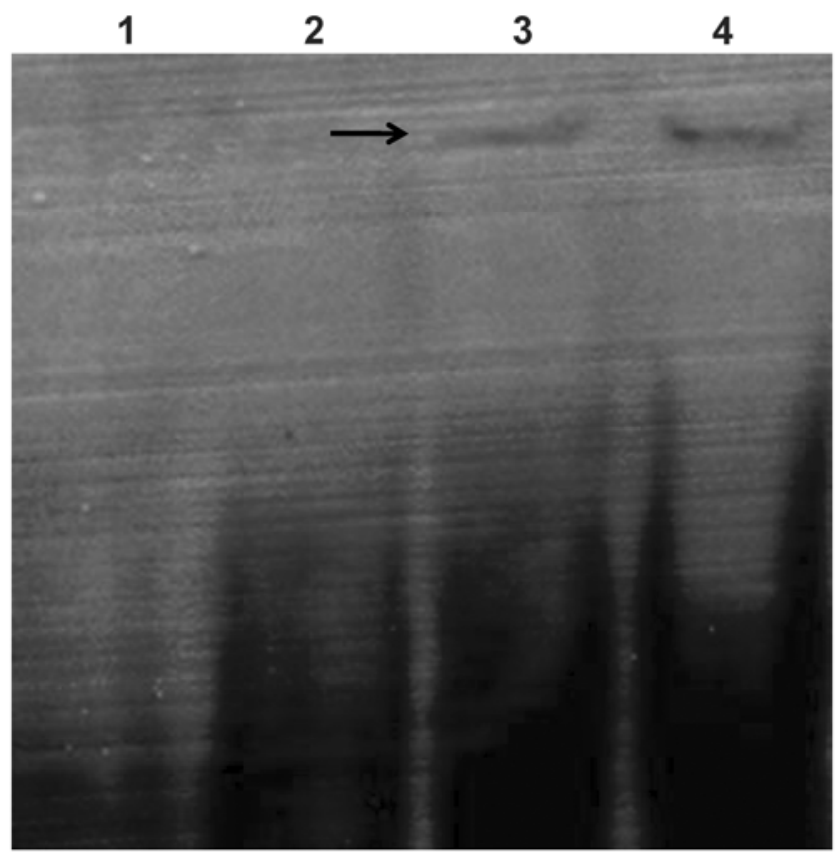

Fig. 5. Gel shift assay of hHsvG with the HSVGT promoter DNA. Oligonucleotides used to obtain the HSVGT promoter are listed in Table 1. Lane 1, oligonucleotides (Bind-Gt-dCo and Bind-Gt-rCo) for generating doublestranded HSVGT promoter with the consensus sequence without hHsvG; lane 2, oligonucleotides (Bind-Gt-d-non and Bind-Gt-r-non) for generating double-stranded HSVGT promoter without the consensus sequence but with $60 \mathrm{ng}$ of hHsvG; lane 3, as in lane 1 but with $30 \mathrm{ng}$ of hHsvG; lane 4, as in lane 1 but with $60 \mathrm{ng}$ of hHsvG. Arrow points to DNA-bound protein. 
virulence effector of Pseudomonas syringe, directly binds Hsp70 through its J-domain, leading to Hsp70 ATP hydrolysis, which appears to be essential for virulence (Jelenska et al. 2010). However, the lack of a chaperon activity in HSVGT rules out the possibility that it is involved in activation of Hsp70 and protein folding. The DnaJ family of proteins share the J-domain region but, outside of this region, the family is greatly divergent and may have very different domain structures (Cheetham and Caplan 1998). Many eukaryotic transcription factors are modular proteins composed of distinct functional domains (Latchman 2008). Several structural motifs of the HSVGT protein could suggest that it might act as a transcription factor in plants (Fig. 3B). These include a putative bipartite NLS, suggesting an import to the nucleus; DNA-binding motifs of the $\mathrm{C}_{2} \mathrm{H}_{2}$ type (or classic) zinc finger and the basic domain leucine zipper (bZIP); as well as the presence of stretches of acidic amino acids (e.g., glutamic and aspartic acids), which are known to be associated with many transcriptional activation domains in eukaryotes (Latchman 2008). $\mathrm{C}_{2} \mathrm{H}_{2}$ zinc finger is one of the most common DNA-binding motifs in eukaryotic transcription factors. Plant zinc-finger proteins play critical regulatory roles by interacting with cis-elements of specific target gene promoters involved in plants stress responses (Ciftci-Yilmaza and Mittlera 2008; Tian et al. 2010). bZIP represents a class of transcription factors that regulate expression of genes in a wide variety of developmental and physiological response pathways in plants and animals (Dong 2004; Sibéril et al. 2001). In plants, bZIP transcription factors constitute a large family which has been implicated in stress signaling, including UV light and salt or drought signaling (Jakoby et al. 2002). Noteworthy are the TGA/OBF family members that interact with NON-EXPRESSOR OF PR1 (NPR1), a key component in salicylic acid signaling (Zhou et al.
2000). Interestingly, OsTFX1, a target gene of the TAL effector pthXo6 from Xanthomonas oryzae pv. oryzae PX099', was reported to act as a bZIP transcription factor in rice, and is involved in mediating host susceptibility (Sugio et al. 2007). The prediction of sumoylation motif in HSVGT suggests that it might be involved in transcription regulation as well as a variety of other biological processes (Miura et al. 2007).

It is noteworthy that the promoter of HSVGT harbors two typical motifs in addition to two TATA boxes (Fig. 3A). Environmentally induced genes almost always contain a TATA box and at least two other cis-elements that may be involved in response to activation by external cues (Buchanan et al. 2000). Housekeeping genes, on the other hand, have less diversity in their cis-elements and may not even contain a recognizable TATA box. Therefore, the promoter structure of HSVGT could reflect characteristics of an environmentally induced gene. Further work will be necessary to find out whether additional target genes for HsvG exist in gypsophila and whether HSVGT does, indeed, act as a transcriptional activator during pathogenesis of $P$. agglomerans pv. gypsophilae.

The rapid induction of HSVGT by HsvG within $2 \mathrm{~h}$ (Fig. 4) is in accordance with the anticipated short period required for translocation of effectors into the host cells via the T3SS (Enninga et al. 2005). The observation that HsvG physically binds to the HSVGT promoter via the consensus sequence (Fig. 5) suggests that it acts as a direct or primary target gene of HsvG. The demonstration that the consensus of HSVGT was responsible for HsvG binding to its promoter raises the hypothesis that it could serve as a conserved promoter element for binding of HsvG to other primary target genes. This could be similar to the UPA box, which binds the AvrBs3 of Xanthomonas campestris pv. vesicatoria to its primary target genes in

Table 1. Sequence of primers used in this study

\begin{tabular}{|c|c|c|}
\hline Primer & Sequence & Used for $^{\mathrm{a}}$ \\
\hline $1 \mathrm{R}$ & 5'-AACTCAAACGGCCATGACTCC-3' & $\ldots$ \\
\hline $1 \mathrm{~L}$ & 5'-AAAGACATGGGCGTCGCGCCTC-3' & Creating pFLAG-HsvG ${ }_{\Delta 115-287}$ \\
\hline $2 \mathrm{R}$ & 5'-GCTGTCAGGCTGCTGCACACG-3' & ... \\
\hline $2 \mathrm{~L}$ & 5'-CGGGACGGTGACCGGGGTTC-3' & Creating pFLAG-HsvG ${ }_{\Delta 530-655}$ \\
\hline $3 \mathrm{R}$ & 5'-AGGCGGCGACGCCCATGTCTTTATCG-3' & $\ldots$ \\
\hline $3 \mathrm{~L}$ & 5'-CGGGTTAATGTTTGTTCCACATGCTGG-3' & Creating pFLAG-HsvG ${ }_{\Delta 8-107}$ \\
\hline $4 \mathrm{R}$ & 5'-GAACCCCGGTCACCGTCCC-3' & $\ldots$ \\
\hline $4 \mathrm{~L}$ & 5'-AATGGAGTCATGGCCGTTTGAG-3' & Creating pFLAG-HsvG ${ }_{\Delta 373-655}$ \\
\hline $5 \mathrm{R}$ & 5'-GGAGAGGACAGCATCACGATACGCG-3' & .. \\
\hline $5 \mathrm{~L}$ & 5'-CGGGTTAATGTTTGTTCCACATGCTGG-3' & Creating pFLAG-HsvG ${ }_{\Delta 8-140}$ \\
\hline IR & 5'-GATACCGCTTACCTGTTCTCGGAGC-3' & $\ldots$ \\
\hline IL & 5'-GTTTTCGTGAAGCCAGGCGCTGAGG-3' & Creating pFLAG-HsvG ${ }_{\Delta 199-204}$ \\
\hline IIR & 5'-GGCAGGGTAAACATGATACTGGCCC-3' & $\ldots$ \\
\hline IIL & 5'-CCGGGAGAACGCACCGGCGTC-3' & Creating pFLAG-HsvG ${ }_{\Delta 224-229}$ \\
\hline IIIR & 5'-GACTCCATTGACAAAAAAGCCTCTCAG-3' & $\ldots$ \\
\hline IIIL & 5'-GGCCTGCCGTGCGAGGTCTTTCG-3' & Creating pFLAG-HsvG ${ }_{\Delta 282-293}$ \\
\hline Mse-1 & 5'-GACGATGAGTCCTGAG-3' & $\ldots$ \\
\hline Mse-2 & 5'-ATGAGTCCTGAGTA-3' & BSS primers and adaptors \\
\hline GudR & 5'-ACAGTGAGGCTGGTGGTGGAT-3' & $\ldots$ \\
\hline GudL & 5'-TCGCGTCCTCCTCCTCAGACC-3' & Cloning of $H S V G T$ \\
\hline GRt-D & 5'-GGGCGTTTCAGGAGCC-3' & $\ldots$ \\
\hline GRt-R & 5'-GCCGCACAATACAGCTCCCTCTTCTCCTC-3' & Real-time PCR of $H S V G T$ \\
\hline Gg-d & 5'-ATGTCTACGATAAGCAAAACAC-3' & $\ldots$ \\
\hline Gg-r & 5'-AAGTTAACACATAGTAGTGTTGC-3' & Glyceraldehydes-3-phosphate dehydrogenase IN \\
\hline Gc-d & 5'-CAGAGAGAAGATGACTCAAATCATG-3' & $\ldots$ \\
\hline Gc-r & 5'-CAGCCTGGATAGCAACATACATAGC-3' & $\operatorname{actin} \mathrm{IN}$ \\
\hline Gt-d & 5'-ATAAGACGAGAACA-3' & $\ldots$ \\
\hline Gt-r & 5'-GGCAGCAGCATTAAATTG-3' & ATPase IN \\
\hline $5 \mathrm{R} 1-\mathrm{R}$ & 5'-TTCCTTATGCTTCTTCGACTG-3' & $\ldots$ \\
\hline 5R2-R & 5'-TCGACCTGCTCATGAATCCTCCAC-3' & Primer for 5' RACE \\
\hline Bind-Gt-dCo & 5'-ATGATGGAAATCATGACACAAAAGGTACAGCAAAGGGTGGAA-3' & $\ldots$ \\
\hline Bind-Gt-rCo & 3'-TTCCACCCTTTGCTGTACCTTTTGTGTCATGATTTCCATCAT-5' & Generating $H S V G T$ promoter region with consensus \\
\hline Bind-Gt-d-non & 5'-GTGATGATGGAAATCATGGTACAGCAAAGGGTGGAAAGAA-3' & $\ldots$ \\
\hline Bind-Gt-r-non & 3'-TTCTTTCCACCCTTTGCTGTACCCATGATTTCCATCATCAC-5' & Generating $H S V G T$ promoter region without consensus \\
\hline
\end{tabular}

${ }^{a} \mathrm{BSS}=$ binding site selection, $\mathrm{PCR}=$ polymerase chain reaction, IN = internal Normalizer, and RACE = random amplification of cDNA ends. 
pepper (Kay et al. 2007, 2009). The observation that HsvG but not HsvB could complement the P. agglomerans pv. gypsophilae-hsvG mutant for activation of HSVGT demonstrates its high specificity to the target gene. Moreover, HsvB converted into HsvG by exchanging their activation domains could fully complement HSVGT. Thus, it further support the premise that host specificity of HsvG and HsvB is determined via the activation domain (Barash and Manulis-Sasson 2009; Nissan et al. 2006) rather than by the DNA-binding domain, as in the case of AvrBs3 effectors (Bogdanove et al. 2010).

The induced expression of HSVGT measured by qRT-PCR could result from activation of transcriptional initiation as well as post-transcriptional regulation. However, it has been previously shown that HsvG is transported into the nucleus by an NLS-mediated process and it acts as a transcription factor in yeast (Nissan et al. 2006; Weinthal et al. 2011). In the present report, we demonstrate that HsvG physically binds to the promoter of its characterized target gene, HSVGT, and induces its expression in a rapid and specific manner. Taken together, these results strongly support the view that HsvG acts as a putative transcription factor in gypsophila.

\section{MATERIALS AND METHODS}

\section{Bacterial strains and growth conditions.}

The bacterial strains, cosmids, and plasmids used in this study are listed in Table 2. Rifampicin-resistant wild-type strain of $P$. agglomerans pv. gypsophilae 824-1 and its derivatives were used throughout. Bacteria were grown in Luria-Bertani (LB) broth and agar or in a minimal medium (Ausubel et al. 1995) at $28^{\circ} \mathrm{C}$ with appropriate antibiotics. Escherichia coli DH5 $\alpha$ (Invitrogen Co., Carlsbad, CA, U.S.A.) was used as cloning host and was grown at $37^{\circ} \mathrm{C}$ on LB plates or in LB broth with the appropriate antibiotics. Antibiotics were used in the following concentrations: ampicillin at $150 \mu \mathrm{g} / \mathrm{ml}$, kanamycin at $30 \mu \mathrm{g} / \mathrm{ml}$, rifampicin at $150 \mu \mathrm{g} / \mathrm{ml}$, and tetracycline at $15 \mu \mathrm{g} / \mathrm{ml}$.

\section{DNA manipulations.}

DNA isolation, agarose gel electrophoresis, electroporation, PCR, and other DNA manipulation methods were performed according to standard procedures (Ausubel et al. 1995) or as recommended by the supplier. DNA fragments were amplified by PCR with Taq polymerase (Sigma-Aldrich, St. Louis) or with Phusion hot start DNA Polymerase (Finnzymes, Keilaranta, Finland), and synthetic oligonucleotides were synthesized according to specification (Sigma-Aldrich).

PCR-amplified DNA or plasmid DNA was purified by a QIAprep spin miniprep kit (Qiagen, Basel, Switzerland) prior to sequencing. Automated sequencing with Taq DNA polymerase was carried out at the Laboratories for Biological Services, Tel-Aviv University using the ABI Prism 3100 Genetic Analyzer. Analysis of sequence data for the DNA and deduced protein sequences was mainly done according to the Program Manual for the Wisconsin Package (version 11; Genetic Computer Group, Madison, WI, U.S.A.).

Deletion mutations in $h s v G$ were generated by employing opposite primers (Table 1) that did not include the desired deletion region, as previously described (Nissan et al. 2006). The primers were designed to create in-frame blunt-ended fragments. PCR was performed with Phusion high-fidelity DNA polymerase (Finnzyme, Espoo, Finland) and the amplified fragments were cloned into the expression vector pFLAGATS (Sigma-Aldrich) and transformed into E. coli DH5 $\alpha$. The proteins were purified as FLAG tag using ANTI-FLAG resin according to instructions of the manufacturer's protocols (Sigma-Aldrich). The deletion mutants were analyzed by mobility shift assays for DNA binding using the Dig labeling kit
(Roche, Mannheim, Germany) following the manufacturer's protocols and according to Nissan and associates (2005).

\section{Binding-site selection.}

HsvG was expressed and purified under native conditions as 6x-his tag HsvG (hHsvG) according to Nissan and associates (2005). Gypsophila paniculata var. perfecta genomic DNA was extracted, digested with $M s e I$, and ligated to MseI adaptors according to the online protocol (Carnegie Institution for Science Department of Biology website). BSS was performed with $\mathrm{HsvG}$ as a binding protein and primers that complement the adaptors, similar to the random binding-site selection procedure described previously (Nissan et al. 2006, Okuno et al. 2001). The binding mixture contained purified hHsvG (30 ng), gypsophila genomic DNA digested with $\mathrm{MseI}$ and ligated to MseI adaptors $(1 \mu \mathrm{g})$, bovine serum albumin $(5 \mu \mathrm{g} / \mathrm{ml})$, EDTA $(125 \mathrm{mM})$, and $3 \mathrm{ml}$ of $1 \times$ binding buffer before the bound oligonucleotides were eluted with $100 \mu \mathrm{l}$ of elution buffer containing $20 \mathrm{mM}$ Tris- $\mathrm{HCl}(\mathrm{pH} 7.5)$ and $3.5 \mu \mathrm{l}$ of $10 \times$ binding buffer $(100 \mathrm{mM}$ Tris- $\mathrm{HCl}, \mathrm{pH} 7.5,50 \%$ glycerol, $10 \mathrm{mM}$ dithiothreitol, and $10 \mathrm{mM}$ EDTA). The mixture was incubated for $30 \mathrm{~min}$ at room temperature. Thereafter, this solution was

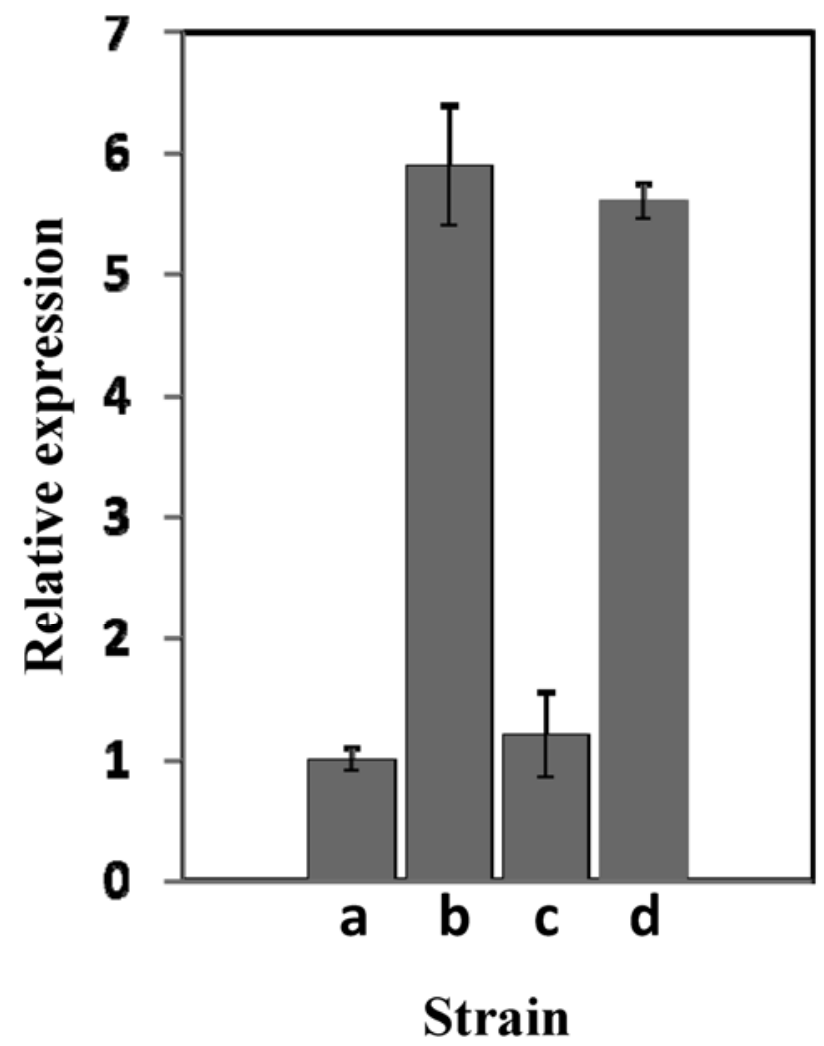

Fig. 6. Relative expression of $H S V G T$ in the $h s v G$ marker exchange mutant in gypsophila cuttings complemented with $h s v G$ or $h s v B$ at $4 \mathrm{~h}$ postinoculation. Bar a, Pantoea agglomerans pv. gypsophilae MxhsvG ( $P$. agglomerans pv. gypsophilae-hsvG mutant); bar b, P. agglomerans pv. gypsophilae MxhsvG/pLHsvG ( $P$. agglomerans pv. gypsophilae-hsvG mutant complemented with $h s v G$ ); bar c, MxhsvG/pLHsvB8 (P. agglomerans pv. gypsophilae-hsvG mutant complemented with $h s v B)$; and bar $\mathrm{d}$, MxhsvG/pLHsvB $\rightarrow \mathrm{G}$ ( $P$. agglomerans pv. gypsophilae-hsvG mutant complemented with $h s v B$ converted to $h s v G$ ). Cuttings were inoculated by dipping in bacterial suspensions $\left(10^{8} \mathrm{CFU} / \mathrm{ml}\right)$ or mock inoculated with 10 $\mathrm{mM} \mathrm{MgCl}_{2}$ solution. Total RNA was extracted from cutting samples collected at various hours postinoculation and used for determination of $H S V G T$ expression by quantitative reverse-transcription polymerase chain reaction analysis. Relative levels of $H S V G T$ were normalized with $\beta$-actin, glyceraldehyde-3-phosphate dehydrogenase, and ATPase as internal references. Results represent the means of three independent experiments with standard deviation. Each experiment included three replicates. 
passed slowly through a presoaked BA85, 0.45- $\mu \mathrm{m}, 25-\mathrm{mm}$ nitrocellulose filter (Schleichter \& Schuell GmbH, Dassel, Germany). The filter was washed three times with $3 \mathrm{ml}$ of $1 \times$ binding buffer before the bound oligonucleotides were eluted with $100 \mu \mathrm{l}$ of elution buffer containing $20 \mathrm{mM}$ Tris- $\mathrm{HCl}(\mathrm{pH}$ 7.5), $1 \mathrm{mM}$ EDTA, $20 \mathrm{mM} \mathrm{NaCl}$, and $0.1 \%$ sodium dodecyl sulfate. The eluate was phenolized and then amplified by PCR using primers Mse-d and Mse-r (Table 1). The amplified product was transferred into the binding reaction mixture and this procedure was repeated. After five rounds of enrichment, the selected oligonucleotides were cloned into pGEM-T Easy (Promega Corp., Madison, WI, U.S.A.), introduced into E. coli DH5 $\alpha$, and sequenced. Thirty DNA fragments were sequenced from randomly selected colonies in each experiment. The sequence related to the target gene (HSVGT) was frequently identified (approximately 80\%) in two independent experiments. The remaining sequences, which did not show any clear repeated pattern or ORF regions, were abandoned.

\section{RACE cDNA amplification.}

Full mRNA sequences were isolated according to the $3^{\prime}$ and $5^{\prime}$ RACE procedure (Frohman 1993). Total RNA was extracted from gypsophila cuttings using the NucleoSpin RNA Plant kit (Machrey-Nagel GmbH \& Co., Duren, Germany) and firststrand synthesis and $3^{\prime}$ or $5^{\prime}$ RACE PCR were carried out by using the Smart RACE cDNA Amplification kit (Clontech Laboratories Inc., Mountain View, CA, U.S.A.) according to the manufacturer's protocols. PCR was performed using internal primers from the known sequences. The PCR fragment was cloned into the PCR cloning vector pGEM-T Easy (Promega Corp.) and sequenced.

\section{qRT-PCR analysis.}

Total RNA was extracted from inoculated cuttings of $G$. paniculata var. perfecta as follows. After removal of an ap- proximately $3-\mathrm{mm}$ section from the bottom of the stem, the cuttings were inoculated by dipping into a bacterial suspension of $10^{8}$ cells $/ \mathrm{ml}$ and placed in vermiculite-filled trays in the greenhouse at 26 to $29^{\circ} \mathrm{C}$. Total RNA was extracted from 100 mg of tissue per treatment. Gene-specific primers for $H S V G T$ (Table 1) were used for PCR amplification. PCR reactions were performed in triplicate and contained template cDNA, $200 \mathrm{nM}$ gene-specific primers, and SYBR Green qPCR master mix (Stratagene, Santa Clara, CA, U.S.A.) in a volume of 15 $\mu l$. Reactions were carried out using an Mx 3000P QPCR System (Stratagene) with the following cycling program: $2 \mathrm{~min}$ at $50^{\circ} \mathrm{C}, 10 \mathrm{~min}$ at $95^{\circ} \mathrm{C}$, followed by 40 cycles of $30 \mathrm{~s}$ at $95^{\circ} \mathrm{C}$, $30 \mathrm{~s}$ at $54^{\circ} \mathrm{C}$, and $30 \mathrm{~s}$ at $72^{\circ} \mathrm{C}$. Fluorescence was monitored at the end of each cycle. The absence of nonspecific products and primer dimers was confirmed by analysis of melting curves and agarose gel electrophoresis according to Balaji and associates (2008). For data analysis, threshold cycle values of three independent biological replicates were averaged, normalized, and used to calculate relative transcript levels as described by Pfaffl (2001). Data were compared using a Student's $t$ test for independent samples (mock versus treated), with the level of significance set at $P<0.05$.

The gypsophila genes selected as internal standards for normalization were actin, glyceraldehyde-3-phosphate dehydrogenase and ATPase. Because the sequence of the gypsophila genome is not available, specific primers for cloning these conserved genes from gypsophila were taken from tomato (Mayrose et al. 2006). Sequences of the above-mentioned genes from gypsophila were used for planning the primers for the housekeeping genes (Table 1).

\section{Bioinformatics methods.}

Secondary structures predictions of the HsvG protein were performed according to Porter (Pollastri and McLysaght 2005), Jpred (Cole et al. 2008), and PSIPRED (Jones 1999). Three

Table 2. Bacterial strains, cosmids, and plasmids used in this study

\begin{tabular}{|c|c|c|}
\hline Strains, plasmids & Relevant characteristics $^{\mathbf{a}}$ & Reference or source \\
\hline DH5 $\alpha$ & Escherichia coli, lacZ $\Delta \mathrm{M} 15 \Delta$ (lacZYA-argF)U169 gyrA96 & Invitrogen \\
\hline \multicolumn{3}{|c|}{ Pantoea agglomerans pv. gypsophilae strains } \\
\hline $824-1$ & Wild-type pathogenic strain with Rif $^{\mathrm{r}}$ & Manulis et al. 1991 \\
\hline MxhsvG & $\begin{array}{l}\text { P. agglomerans pv. gypsophilae 824-1, marker exchange mutant in hsv } G \text { (previously P. agglomerans } \\
\text { pv. gypsophilae MxB45) }\end{array}$ & Valinsky et al. 1998 \\
\hline \multicolumn{3}{|c|}{ 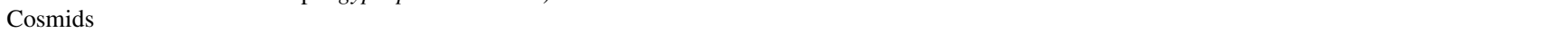 } \\
\hline pLAFR3 & $\mathrm{Tc}^{\mathrm{r}}$, broad-host-range vector $I n c P-1$ rixRK2+ lacZa Tra- Mob+ cos & Staskawicz et al. 1987 \\
\hline pLHsvG & $\mathrm{Tc}^{\mathrm{r}}, h s v G-P a g$ under its own promoter cloned into pLAFR3 as an HindIII/Bam HI fragment & Valinsky et al. 1998 \\
\hline pLHsvB8 & $\mathrm{Tc}^{\mathrm{r}}$, hsvB-Pag under its own promoter cloned into pLAFR3 as an HindIII/BamHI fragment & Nissan et al. 2006 \\
\hline $\mathrm{pLHsvB} \rightarrow \mathrm{G}$ & $\begin{array}{l}\mathrm{Tc}^{\mathrm{r}}, \text { hsvB-P. agglomerans pv. betae with addition in frame of RI of } h s v G \text { cloned into pLAFR } 3 \text { as an } \\
\text { HindIII/Bam HI fragment }\end{array}$ & Nissan et al. 2006 \\
\hline \multicolumn{3}{|c|}{ 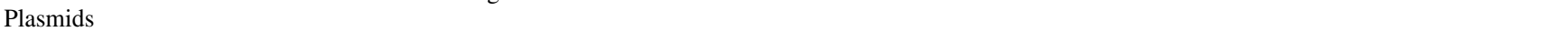 } \\
\hline pQE70 & $\mathrm{Ap}^{\mathrm{r}}$, His-tag expression vector & Qiagen \\
\hline pHsvG-his & $\mathrm{Ap}^{\mathrm{r}}$, PCR-amplified $h s v G$ coding sequence cloned into $\mathrm{pQE70}$ as a $S p h \mathrm{I} /$ BamHI fragment & Nissan et al. 2006 \\
\hline pGEM-T Easy & $\mathrm{Ap}^{\mathrm{r}}, \mathrm{PCR}$ cloning vector & Promega \\
\hline pFLAG-ATS & $\mathrm{Ap}^{\mathrm{r}}$, Expression and secretion of N-terminal FLAG-fusion proteins under tac promoter & Sigma-Aldrich \\
\hline pFLAG-HsvG & $\mathrm{Ap}^{\mathrm{r}}$, HsvG with a deletion in 115 to 287 amino acids (aa) & This study \\
\hline pFLAG-HsvG ${ }_{\triangle 8-107}$ & $\mathrm{Ap}^{\mathrm{r}}, \mathrm{HsvG}$ with a deletion in 8 to 107 aa & This study \\
\hline pFLAG-HsvG & $\mathrm{Ap}^{\mathrm{r}}, \mathrm{HsvG}$ with a deletion in 8 to 140 aa & This study \\
\hline pFLAG-HsvG $\triangle 4530-655$ & $\mathrm{Ap}^{\mathrm{r}}, \mathrm{HsvG}$ with a deletion in 530 to 655 aa & This study \\
\hline pFLAG-HsvG $\triangle{ }_{\triangle 373-655}$ & $\mathrm{Ap}^{\mathrm{r}}, \mathrm{HsvG}$ with a deletion in 373 to 655 aa & This study \\
\hline pFLAG-HsvG & $\mathrm{Ap}^{\mathrm{r}}, \mathrm{HsvG}$ with a deletion in 199 to 204 aa & This study \\
\hline pFLAG-HsvG ${ }_{\Delta 224-229}$ & $\mathrm{Ap}^{\mathrm{r}}, \mathrm{HsvG}$ with a deletion in 224 to $229 \mathrm{aa}$ & This study \\
\hline pFLAG-HsvG ${ }_{\triangle 282-293}$ & $\mathrm{Ap}^{\mathrm{r}}, \mathrm{HsvG}$ with a deletion in 282 to 293 aa & This study \\
\hline pGEM-GP & $\mathrm{Ap}^{\mathrm{r}}$, cloning of BSS products & This study \\
\hline pGEM-G3'RACE & Ap ${ }^{r}$, cloning of gypsophila $3^{\prime}$ RACE products & This study \\
\hline pGEM-HSVGT & $\mathrm{Ap}^{\mathrm{r}}$, PCR-amplified $H S V G T$ coding sequence & This study \\
\hline pGEM-GAc & $\mathrm{Ap}^{\mathrm{r}}$, PCR-amplified fragment of Actin gene from the gypsophila & This study \\
\hline pGEM-GGly & $\mathrm{Ap}^{\mathrm{r}}$, PCR-amplified fragment of glyceraldehyde-3-phosphate dehydrogenase gene from gypsophila & This study \\
\hline pGEM-GAt & $\mathrm{Ap}^{\mathrm{r}}$, PCR-amplified fragment of ATPase gene from gypsophila & This study \\
\hline
\end{tabular}

${ }^{\mathrm{a}} \mathrm{Rif}^{\mathrm{r}}, \mathrm{Tc}^{\mathrm{r}}$, and $\mathrm{Ap}^{\mathrm{r}}$ indicate resistance to rifampicin, tetracycline, and ampicillin, respectively. 
different methods were employed to predict the fold recognition of HsvG, namely, 3D-JURY, HHPRED and FFAS03 (Ginalski et al. 2002; Jaroszewski et al. 2005; Söding 2005). Promoter motif prediction for HSVGT was carried out by the MEME-ChIP server according to Baily and Elkan (1994) and Milanesi and associates (1996). TATA-box prediction was made by Zeus2 (Milanesi et al. 1996).

Sequences homologous to the HSVGT protein were found using a CS-Blast search (Biegert and Soding 2009) on NCBI and Uniprot databases. Hypothetical proteins were omitted and the resulting 38 homologs were aligned using Mafft (Katho et al. 2002). A nuclear localization sequence was predicted by Predict NLS (Nguyen Ba et al. 2009). DNA binding prediction in HSVGT was obtained by the following two servers: DBSPRED predictions (Ahmad et al. 2004) and DB-Bind (Hwang et al. 2007). SUMOylation prediction was made by SUMOsp 2.0 (Ren et al. 2009). Various motifs and domains such as SnF_C2H2 and bZIP were located as presented in the UniProt database. Conservation analysis was performed by the Conseq server (Berezin et al. 2004). Servers used for prediction of helix-turn-helix or helix-loop-helix are listed below.

\section{ACKNOWLEDGMENTS}

This study was supported by the Israel Science Foundation (grant number 847/07).

\section{LITERATURE CITED}

Ahmad, S., Gromiha, M. M., and Sarai, A. 2004. Analysis and prediction of DNA-binding proteins and their binding residues based on composition, sequence and structure information. Bioinformatics 20:477-486.

Ausubel, F. M., Brent, R., Kingston, R. E., Moore, D. D., Seidman, J. G, Smith, J. A., and Struhl, K. eds. 1995. Current Protocols in Molecular Biology. John Wiley \& Sons, Inc., New York.

Baily, T. L., and Elkan, C. 1994. Fitting a mixture model by expectation maximization to discover motifs in biopolymers. Pages 28-36 in: Proceedings of the Second International Conference on Intelligent Systems for Molecular Biology, Vol 2. The Association for the Advancement of Artificial Intelligence (AAAI) Press, Menlo Park, CA, U.S.A.

Balaji, V., Jacob-Hirsh, J., Sherf, O., Eichenlaub, R., Iraki, N., ManulisSasson, S., Rechavi, G., Barash I., and Sessa, G. 2008. Tomato transcriptional changes in response to Clavibacter michiganensis subsp. michiganensis reveal a role for ethylene in disease development. Plant Physiol. 146:1797-1809.

Barash, I., and Manulis-Sasson, S. 2007. Virulence mechanisms and host specificity of gall-forming Pantoea agglomerans. Trends Microbiol. $15: 538-545$

Barash, I., and Manulis-Sasson, S. 2009. Recent evolution of bacterial pathogens: The gall-forming Pantoea agglomerans case. Annu. Rev. Phytopathol. 47:133-152.

Berezin, C., Glaser, F., Rosenberg, Y., Paz, I., Pupko, T., Fariselli, P., Casadio, R., and Ben-Tal, N. 2004. The identification of functionally and structurally important residues in protein sequences. Bioinformatics 20:1322-1324.

Biegert, A., and Soding, J. 2009. Sequence context-specific profiles for homology searching. Proc. Natl. Acad. Sci. U.S.A. 106:3770-3775.

Boch, J., and Bonas, U. 2010. Xanthomonas AvrBs3 family-type III effectors: Discovery and function. Annu. Rev. Phytopathol. 48:419-436.

Boch, J., Scholze, H., Schornack, S., Landgraf, A., Hahn, S., Kay, S., Lahaye, T., Nickstadt, A., and Bonas, U. 2009. Breaking the code of DNA binding specificity of TAL-type III effectors. Science 326:15091512.

Bogdanove, A. J., Schornack, S., and Lahaye, T. 2010. TAL effectors: Finding plant genes for disease and defense. Curr. Opin. Plant Biol. 13:394-401.

Buchanan, B. B., Gruissem, W., and Jones, R. L. 2000. Biochemistry and Molecular Biology of Plants. American Society of Plant Physiology, Rockville, MD, U.S.A

Burr, T. J., Katz, B. H., Abawi, G. S., and Crosier, D. C. 1991. Comparison of tumorigenic strains of Erwinia herbicola isolated from table beet with E. herbicola pv. gypsophilae. Plant Dis. 75:855-858.

Cheetham, M. E., and Caplan, A. J. 1998. Structure, function and evolution of DnaJ: Conservation and adaptation of chaperon function. Cell Stress Chaperon. 3:28-36.
Ciftci-Yilmaza, S., and Mittlera, R. 2008. The zinc finger network of plants. Cell. Mol. Life Sci. 65:1150-1160.

Clark, E., Manulis, S., Ophir, Y., Barash, I, and Gafni, Y. 1993. Cloning and characterization of iaaM and iaaH from Erwinia herbicola pathovar gypsophilae. Phytopathology 83:234-240.

Cole, C., Barber, J. D., and Barton, G. J. 2008. The Jpred 3 secondary structure prediction server. Nucleic Acids Res. 36 (Suppl. 2):W197W201.

Cooksey, D. A. 1986. Galls of Gypsophila paniculata caused by Erwinia herbicola. Plant Dis. 70:464-468.

Dong, X. 2004. NPR1, all things considered. Curr. Opin. Plant Biol. 7:547-552.

Enninga, J., Mounier, J., Sansonetti, P., and Tran Van Nhieu, G. 2005. Secretion of type III effectors into host cells in real time. Nat. Methods 2:959-965.

Ezra, D., Barash I., Valinsky L., and Manulis, S. 2000. The dual function in virulence and host range restriction of a gene isolated from the pPATH $_{\text {Ehg }}$ plasmid of Erwinia herbicola pv. gypsophilae. Mol. PlantMicrobe Interact. 13:683-692.

Frohman, M. A. 1993. Rapid amplification of complementary DNA ends for generation of full-length complementary DNAs: Thermal RACE. Methods Enzymol. 218:340-356.

Ginalski, K., Elofsson, A., and Fischer, D. L. R. 2002. 3D-Jury: A simple approach to improve protein structure predictions. Bioinformatics 19:1015-1018.

Gurlebeck, D., Thieme, F., and Bonas, U. 2006. Type III effector proteins from the plant pathogen Xanthomonas and their role in interaction with the host plant. J. Plant Physiol. 163:233-255.

Hennessy, F., Nicoll, W. S., Zimmermann, R., Cheetham, M. E., and Blatch, G. L. 2005. Not all J domains are created equal: Implications for the specificity of Hsp40-Hsp70 interactions. Prot. Sci. 17:1697-1709.

Hwang, S., Gou, Z., and Kuznetsov, I. B. 2007. DP-Bind: A web server for sequence-based prediction of DNA-binding residues in DNA-binding proteins. Bioinformatics 23:634-636.

Jakoby, M., Weisshaar, B., Droge-Laser, W., Vicente-Carbajosa, J. Tiedemann, J., Kroj, T., and Parcy, F. 2002. bZIP transcription factors in Arabidopsis. Trends Plant Sci. 7:106-111.

Jaroszewski, L., Rychlewski, L., Li, Z., Li, W., and Godzik, A. 2005. FFAS03: A server for profile-profile sequence alignments. Nucleic Acids Res. 33:W284-W288.

Jelenska, J., van Hal, J. A., and Greenberg, J. T. 2010. Pseudomonas syringae hijacks plant stress chaperon machinery for virulence. Proc. Natl. Acad. Sci. U.S.A. 107:13177-13182.

Jones, D. T. 1999. Protein secondary structure prediction based on position-specific scoring matrices. J. Mol. Biol. 292:195-202.

Katho, K., Misawa, K., Kuma, K.-I., and Miyata, T. 2002. MAFFT: A novel method for rapid multiple sequence alignment based on fast Fourier transform. Nucleic Acids Res. 30:3059-3066.

Kay, S., Hahn, S., Marois, E., Hause, G., and Bonas, U. 2007. A bacterial effector acts as a plant transcription factor and induces a cell size regulator. Science 318:648-651.

Kay, S., Hahn, S., Marois, E., Wieduwild, R., and Bonas, U. 2009. Detailed analysis of DNA recognition motifs of Xanthomonas type III effectors AvrBs3 and AvrBs3 rep16. Plant J. 59:859-871.

Kelly, W. L. 1998. The J-domain family and the recruitment of chaperone power. Trends Biochem. Sci. 23:222-227.

Latchman, D. S. 2008. Eukaryotic Transcription Factors. Academic Press. New York.

Lichter, A., Barash, I., Valinsky, L., and Manulis, S. 1995. The genes involved in cytokinin biosynthesis in Erwinia herbicola pv. gypsophilae: Characterization and role in gall formation. J. Bacteriol. 177:44574465.

Manulis, M., and Barash, I. 2003. The molecular basis for transformation of an epiphyte into a gall-forming pathogen as exemplified by Erwinia herbicola pv. gypsophilae. Pages 19-52 in: Plant-Microbe Interactions, vol. 6. G. Stacey and N. Keen, eds. American Phytopathological Society, St. Paul, MN, U.S.A.

Manulis, S., Gafni, Y., Clark, E., Zutra, D., Ophir, Y., and Barash, I. 1991. Identification of a plasmid DNA probe for detection of Erwinia herbicola pathogenic on Gypsophila paniculata. Phytopathology 81:54-57.

Marois, E., Van den Ackerveken, G., and Bonas, U. 2002. The Xanthomonas type III effector protein AvrBs3 modulates plant gene expression and induces cell hypertrophy in the susceptible host. Mol. PlantMicrobe Interact. 15:637-646.

Mayrose, M., Ekengren, S. K., Melech-Bonfil, S., Martin, G. B., and Sessa, G. 2006. A novel link between tomato GRAS genes, plant disease resistance and mechanical stress response. Mol. Plant Pathol. 6:593-604.

Milanesi, L., Muselli, M., and Arrigo, P. 1996. Hamming-Clustering method for signals prediction in $5^{\prime}$ and $3^{\prime}$ regions of eukaryotic genes. Comput. Appl. Biosci. 12:399-404. 
Miura, P. M. K., Jin, J. B., and Hasegawaa, P. M. 2007. Sumoylation, post-translational regulatory process in plants. Curr. Opin. Plant Biol. 10:495-502.

Mor, H., Manulis, S., Zuc, M., Nizan, R., Coplin, D. L., and Barash I. 2001. Genetic organization of the hrp gene cluster and dspAE/BF operon in Erwinia herbicola pv. gypsophilae. Mol. Plant-Microbe Interact. 14:431-436

Moscou, M. J., and Bogdanove, A. J. 2009. A simple cipher governs DNA recognition by TAL effectors. Science 326:1501.

Nguyen Ba, A. N., Pogoutse, A., Provart, N., and Moses, A. M. 2009. NLStradamus: A simple Hidden Markov Model for nuclear localization signal prediction. BMC Bioinformatics 10:202.

Nissan, G., Manulis, S., Weinthal, D., Sessa, G., and Barash, I. 2005. Analysis of promoters recognized by $\mathrm{HrpL}$, an alternative sigma-factor protein from Pantoea agglomerans pv. gypsophilae. Mol. Plant-Microbe Interact. 18:634-643.

Nissan, G., Manulis-Sasson, S., Weinthal, D. M., Mor, H., Sessa, G., and Barash, I. 2006. The type III effectors HsvG and HsvB of gall-forming Pantoea determine host specificity and function as transcriptional activators. Mol. Microbiol. 61:1118-1131.

Nizan, R., Barash, I., Valinsky, L., Lichter, A., and Manulis, S. 1997. The presence of hrp genes on the pathogenicity-associated plasmid of the tumorigenic bacterium Erwinia herbicola pv. gypsophilae. Mol. PlantMicrobe Interact. 10:677-682.

Nizan-Koren, R., Manulis, S., Mor, H., Iraki, N. M., and Barash, I. 2003. The regulatory cascade that activates the Hrp regulon in Erwinia herbicola pv. gypsophilae. Mol. Plant-Microbe Interact. 16:249-260.

Okuno, M., Arimoto, E., Ikenobu, Y., Nishiara, T., and Imagawa, M. 2001. Dual DNA binding specificity of peroxisome-proliferator-activated receptor gamma controlled by heterodimer formation with retinoid $\mathrm{X}$ receptor alpha. Biochem. J. 353:241-249.

Pfaffl, M. W. 2001. A new mathematical model for relative quantification in real-time RT-PCR. Nucleic Acids Res. 29:e45.

Pollastri, G., and McLysaght, A. 2005. Porter: A new, accurate server for protein secondary structure prediction. Bioinformatics 21:1719-1720.

Ren, J., Gao, X., Jin, C., Zhul, M., Wang, X., Shaw, A., Wen, L., Yao, X., and Xue, Y. 2009. Systematic study of protein sumoylation: Development of a site-specific predictor of SUMOsp 2.0. Proteomics 9:3409-3412.

Römer, P., Strauss, T., Hahn, S., Scholze, H., Morbitzer, R., Grau, J., Bonas, U., and Lahaye, T. 2009. Recognition of AvrBs3-like proteins is mediated by specific binding to promoters of matching pepper Bs3 alleles. Plant Physiol. 150:1697-1712.

Sibéril, Y., Doireau, P., and Gantet, P. 2001. Plant bZIP G-box binding factors. Eur. J. Biochem. 268:5655-5666.

Söding, J. 2005. Protein homology detection by HMM-HMM comparison. Bioinformatics 21:951-960.

Staskawicz, B., Dahlbeck, D., Keen, N., and Napoli, C. 1987. Molecular characterization of cloned avirulence genes from race 0 and race 1 of Pseudomonas syringae pv. glycinea. J. Bacteriol. 169:5789-5794.

Sugio, A., Yang, B., Zhu, T., and White, F. F. 2007. Two type III effector genes of Xanthomonas oryzae pv. oryzae control the induction of the host genes OsTFA $\gamma 1$ and OsTFX1 during bacterial blight of rice. Proc. Natl. Acad. Sci. U.S.A. 104:10720-10725.

Tian, Z.-D., Zhang, Y., Liu, J., and Xie, C.-H. 2010. Novel potato $\mathrm{C}_{2} \mathrm{H}_{2}$ type zinc finger protein gene, $S t Z F P 1$, which responds to biotic and abiotic stress, plays a role in salt tolerance. Plant Biol. 12:689-697.

Valinsky, L., Manulis, S., Nizan, R., Ezra, D., and Barash, I. 1998. A pathogenicity gene isolated from the pPATH of Erwinia herbicola pv. gypsophila determines host specificity. Mol. Plant-Microbe Interact. 11:753-762.

Weinthal, D., Barash, I., Tzfira, T., Gaba, V., Teper, D., Sessa, G., and Manulis-Sasson, S. 2011. Characterization of nuclear localization signals in the type III effectors HsvG and HsvB of the gall-forming bacterium Pantoea agglomerans. Microbiology 157:1500-1508.

Zhou, J.-M., Trifa, Y., Silva, H., Pontier, D., Lam, E., Shah, J., and Klessig, D. F. 2000. NPR1 differentially interacts with members of the TGA/ OBF family of transcription factors that bind an element of the PR-1 gene required for induction by salicylic acid. Mol. Plant-Microbe Interact. 13:191-202.

\section{AUTHOR-RECOMMENDED INTERNET RESOURCES}

Carnegie Institution for Science Department of Biology website: www-ciwdpb.stanford.edu/publications/methods/aflp.html

Conseq server: conseq.tau.ac.il

DBS-PRED prediction server: gibk26.bio.kyutech.ac.jp/jouhou/shandar/netasa/dbs-pred

EMBOSS Explorer helixturnhelix server: bioinformatica.cecalc.ula.ve/cgibin/emboss/helixturnhelix

GYM 2.0 helix-turn-helix detection program: http://users.cis.fiu.edu/ giri/bioinf/GYM2/welcome.html

MEME Suite analysis tools: meme.nbcr.net/meme/intro.html

Pôle BioInformatique Lyonnais helix-turn-helix motif prediction server: npsa-pbil.ibcp.fr/cgi-bin/npsa_automat.pl?page=/NPSA/npsa_hth.html Prediction of or helix-loop-helix

SUMOsp server: sumosp.biocuckoo.org/online.php

UniProt database: www.uniprot.org

University of Albany DB-Bind server: lcg.rit.albany.edu/dp-bind/

University of Toronto NLStradamus webpage: www.moseslab.csb.utoronto.ca/NLStradamus

Webgene Zeus 2 analysis tool: zeus2.itb.cnr.it/ webgene/wwwHC_tata.html 